\title{
Measurements of greenhouse gases at Beromünster tall-tower station in Switzerland
}

\author{
Tesfaye Ayalneh Berhanu ${ }^{1}$, Ece Satar ${ }^{1}$, Rudiger Schanda ${ }^{1}$, Peter Nyfeler ${ }^{1}$, Hanspeter Moret $^{1}$, Dominik Brunner ${ }^{2}$, \\ Brian Oney $^{2,3}$, and Markus Leuenberger ${ }^{1}$ \\ ${ }^{1}$ Physics Institute and Oeschger Center for Climate Change Research, University of Bern, Bern, Switzerland \\ ${ }^{2}$ Empa, Laboratory for Air Pollution/Environmental Technology, Dübendorf, Switzerland \\ ${ }^{3}$ ETH Zurich, Center for Climate Systems Modeling, Zurich, Switzerland
}

Correspondence to: T. A. Berhanu (berhanu@ climate.unibe.ch)

Received: 6 June 2015 - Published in Atmos. Meas. Tech. Discuss.: 21 October 2015

Revised: 18 May 2016 - Accepted: 1 June 2016 - Published: 17 June 2016

\begin{abstract}
In order to constrain the regional flux of greenhouse gases, an automated measurement system was built on an old radio tower at Beromünster, Switzerland. The measurement system has been running since November 2012 as part of the Swiss greenhouse gases monitoring network (CarboCount- $\mathrm{CH}$ ), which is composed of four measurement sites across the country. The Beromünster tall tower has five sampling lines with inlets at 12.5, 44.6, 71.5, 131.6, and $212.5 \mathrm{~m}$ above ground level, and it is equipped with a Picarro cavity ring-down spectrometer (CRDS) analyzer (G2401), which continuously measures $\mathrm{CO}, \mathrm{CO}_{2}, \mathrm{CH}_{4}$, and $\mathrm{H}_{2} \mathrm{O}$. Sensors for detection of wind speed and direction, air temperature, barometric pressure, and humidity have also been installed at each height level. We have observed a non-negligible temperature effect in the calibration measurements, which was found to be dependent on the type of cylinder (steel or aluminum) as well as trace gas species (strongest for $\mathrm{CO}$ ). From a target gas of known mixing ratio that has been measured once a day, we have calculated a long-term reproducibility of $2.79 \mathrm{ppb}, 0.05 \mathrm{ppm}$, and $0.29 \mathrm{ppb}$ for $\mathrm{CO}$, $\mathrm{CO}_{2}$, and $\mathrm{CH}_{4}$, respectively, over 19 months of measurements. The values obtained for $\mathrm{CO}_{2}$ and $\mathrm{CH}_{4}$ are compliant with the WMO recommendations, while the value calculated for $\mathrm{CO}$ is higher than the recommendation. Since the installation of an air-conditioning system recently at the measurement cabin, we have acquired better temperature stability of the measurement system, but no significant improvement was observed in the measurement precision inferred from the target gas measurements. Therefore, it seems that the observed higher variation in $\mathrm{CO}$ measurements is associated with the
\end{abstract}

instrumental noise, compatible with the precision provided by the manufacturer.

\section{Introduction}

The rapid increase in anthropogenic greenhouse gas emissions since the Industrial Revolution is expected to have adverse effects on the global climate if no drastic emissions reduction measures are taken soon (IPCC, 2013). In order to understand the current climate system and to make reliable predictions, it is essential to accurately quantify the global budget of these greenhouse gases. First approaches involved measurements at remote locations, excluding continental sites to avoid complications in data interpretation arising from sources in the vicinity of the measurement site. However, these measurements were suitable only to constrain global or hemispheric-scale fluxes; they were not able to address local to regional scales (Gloor et al., 2000). The necessity to include continental sites for a better understanding of the carbon cycle and greenhouse gas exchange processes was emphasized already in the early 1990s (Tans, 1991). Tall-tower measurements combined with transport models were proposed as a suitable approach to constraining regional-scale greenhouse gas fluxes via inverse modeling (Tans, 1993). Measurements from tall towers enable probing the well-mixed part of the planetary boundary layer with minimal influence from potentially strong local surface fluxes, and therefore obtaining information for a relatively large area surrounding the site. For example, a trajectory 


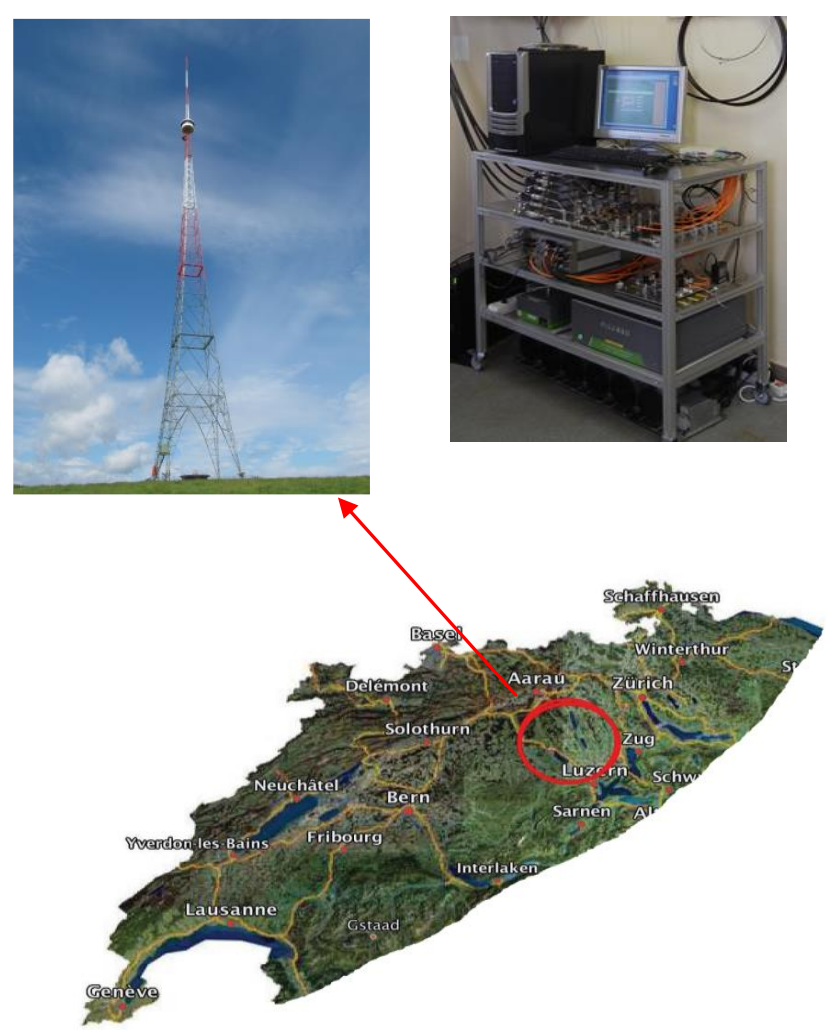

Figure 1. Geographical location of the Beromünster tall tower and pictures of the tower and of the measurement rack with the Picarro G-2410 CRDS analyzer on the lower shelf and electronics, flow control, and computer on the upper shelves.

analysis conducted for the Wisconsin tower of $396 \mathrm{~m}$ above ground level (a.g.l.) indicated that the measurements are representative for a concentration footprint of an area as large as $10^{6} \mathrm{~km}^{2}$ around the tower (Gloor et al., 2001).

In the past decades, a number of tall-tower sites have been established across the globe in order to constrain regional fluxes of greenhouse gases (Bakwin et al., 1995; Haszpra et al., 2001; Thompson et al., 2009; Popa et al., 2010; Winderlich et al., 2010; Vermeulen et al., 2011; Andrews et al., 2014). The European network of tall-tower sites was first established under the umbrella of the CHIOTTO project (Continuous HIgh-precisiOn Tall Tower Observations of greenhouse gases; Vermeulen et al., 2004) and is currently being expanded in the framework of the European infrastructure project ICOS (Integrated Carbon Observation System; www.icos-infrastructure.eu).

The main objective of this paper is to briefly describe a new tall-tower station in Switzerland established within the CarboCount-CH project (Oney et al., 2015), which is mainly designed to quantify the greenhouse gas budget on the Swiss Plateau. The measurement system has been in operation since November 2012, and it has access to five sampling heights up to $212.5 \mathrm{~m}$ a.g.l. Here, we focus on technical details of the measurement system, elaborate on data evaluation protocols, and analyze the performance and accuracy of the measurements. Detailed interpretation of the data is presented by Satar et al. (2016) and additional results will be the topic of future work.

\section{Site description and methodology}

\subsection{Site description}

The Beromünster tall tower $\left(47^{\circ} 11^{\prime} 23^{\prime \prime} \mathrm{N}, 8^{\circ} 10^{\prime} 32^{\prime \prime} \mathrm{E}\right)$ is located near the southern border of the Swiss Plateau, the comparatively flat part of Switzerland between the Alps in the south and the Jura Mountains in the northwest, which is characterized by intense agriculture and a high population density. The tower was built in 1937 for medium-wave radio transmission and has a height of $217 \mathrm{~m}$. The site is located on a gentle hill with an elevation of $797 \mathrm{~m}$ a.s.l. between the small towns of Sursee (6 km to the southwest) and Beromünster ( $2 \mathrm{~km}$ to the northeast), with an estimated population of 9100 and 4800, respectively (Fig. 1). Further details about the site, the local environment, wind conditions, and the concentration footprint (area of sensitivity to regional sources) are presented in Oney et al. (2015).

\subsection{Methodology}

\subsubsection{Ambient air sampling and airflow system}

Figure 2 describes the Beromünster tall-tower $\mathrm{CO}-\mathrm{CO}_{2}-$ $\mathrm{CH}_{4}-\mathrm{H}_{2} \mathrm{O}$ analysis system, which inherits most of its design elements from the Zotino Tall Tower Observatory (ZOTTO) in central Siberia (Winderlich et al., 2010). Ambient air is drawn down the tower through five sampling lines (Synflex 1300 tubing, OD/ID $12 \mathrm{~mm} / 8 \mathrm{~mm}$, Eaton) with inlets at 12.5 , 44.6, 71.5, 131.6, and $212.5 \mathrm{ma}$ a.g.l. and at a flow rate of $14 \mathrm{~L} \mathrm{~min}^{-1}$ (at ambient conditions) by using five identical membrane pumps (CF1-CF5) (617CD32, Gardner Denver, USA). With this high flow rate, wall effects are minimized, and the residence time of the ambient air in the longest sampling line is limited to approximately $0.8 \mathrm{~min}$. A $40 \mu \mathrm{m}$ coarse filter (Swagelok SS-12TF-MM-40) is placed before each tubing inlet to prevent particles from entering the system. As the analytical system requires only $160 \mathrm{~mL} \mathrm{~min}^{-1}$ (at ambient conditions) of this high airflow, the excess air is purged via exhaust pumps (CF1-CF5) connected to the sampling lines via T-junctions. The excess airflow to these pumps is adjusted using needle valves (NV1-NV5). The small fraction of ambient air that is directed towards the analyzer is additionally filtered using a $2 \mu \mathrm{m}$ filter. As the highest pressure drop (approximately 240 mbar) occurs in the $212.5 \mathrm{~m}$ level sampling line (longest sampling tube), no needle valve is present in this sampling line. Needle valves (NV6-NV9) are used to adjust the pressure at the end of the other sampling lines to the pressure of the $212.5 \mathrm{~m}$ line, in order to 


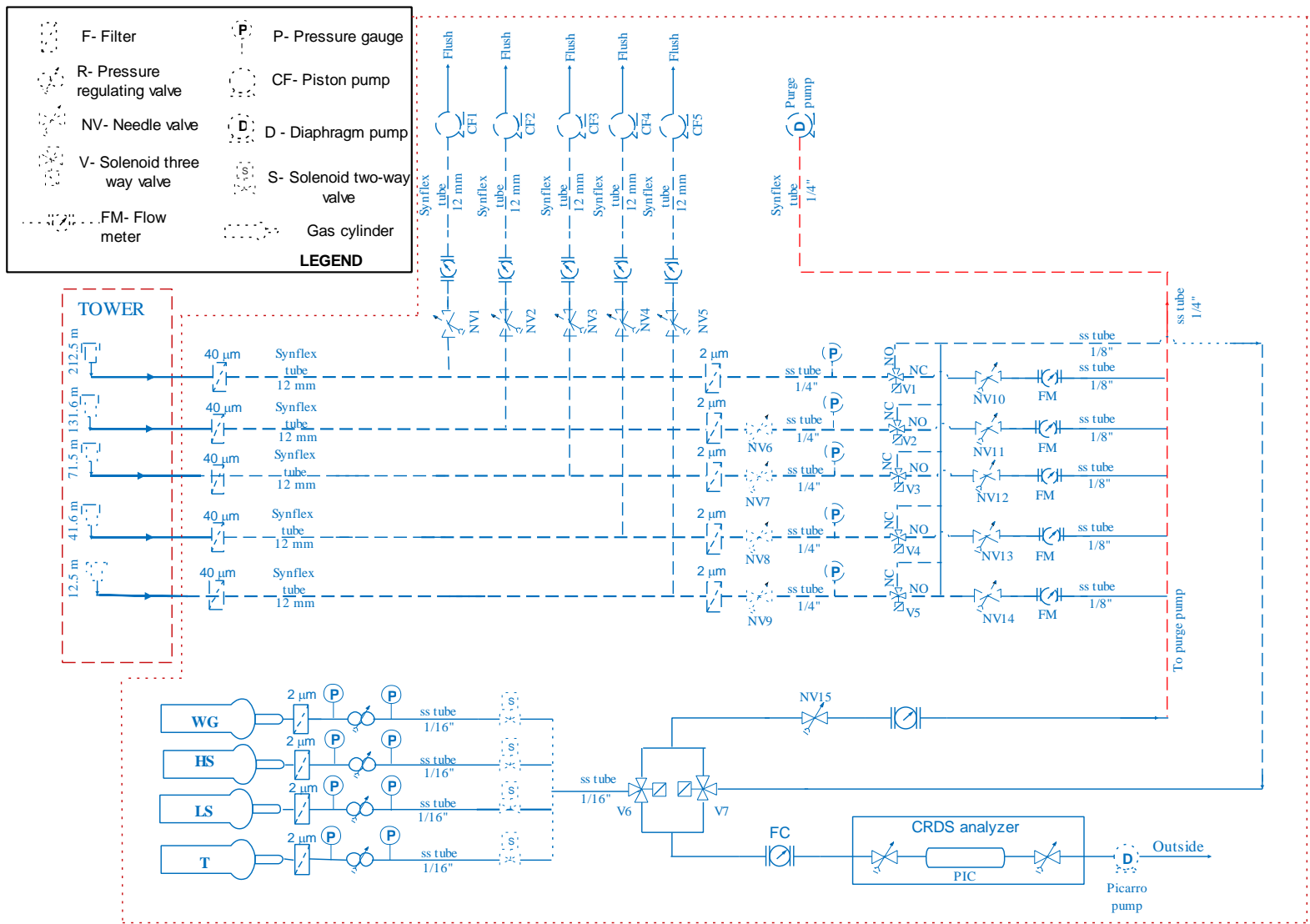

Figure 2. Schematic of the Beromünster greenhouse gases measurement system.

avoid large pressure jumps when switching between the different inlets and to maintain a uniform ambient airflow towards the analyzer. The three-way valves (V1-V5) (G3414, Gems Sensors and Controls, USA) are switched consecutively so that, while sample air from a given height is directed towards the analyzer, the remaining gas from the other four inlets is purged (N86KNE, KNF Neuberger GmbH, Germany). The purge flow from these lines is again controlled by manual needle valves (NV10-NV14) and flow meters to approximately $160 \mathrm{~mL} \mathrm{~min}^{-1}$ each.

The system can choose between measurements of standards (cylinder gases) or ambient air using three-way solenoid valves (V6 and V7). The flow of the gas of choice to the analyzer is adjusted using a flow controller (AnalytMTC 0-500 SCCM, Aalborg, USA). The analyzer is a Picarro cavity ring-down spectrometer (CRDS) (G-2401, Picarro, USA) which measures the mixing ratios of $\mathrm{CO}_{2}, \mathrm{CH}_{4}$, $\mathrm{CO}$, and $\mathrm{H}_{2} \mathrm{O}$. Drying of the sample air is not applied, but the measurements rely on the manufacturer-supplied correction with an accuracy within the Global Atmospheric Watch (GAW) compatibility limits up to ambient water vapor mixing ratios of at least $1 \%$ (Rella et al., 2013) for $\mathrm{CO}_{2}$ and $\mathrm{CH}_{4}$ measurements. In the case of $\mathrm{CO}$, uncertainty in the measured mixing ratios is expected due to dilution and pressure- broadening effects as well as line interference from adjacent $\mathrm{CO}_{2}$ and $\mathrm{H}_{2} \mathrm{O}$ absorption lines (Chen et al., 2013), which are not accounted for in the reported mixing ratios. However, this will have a minor effect on the ambient air measurements as the natural $\mathrm{CO}$ variability is significantly higher. The measurement system is housed inside the small, circularshaped ( $\sim 6 \mathrm{~m}$ diameter) former radio transmitter building at the base of the tower. The building is made of concrete and an air-conditioning system has been installed on 18 May 2015 (see Sect. 3.4). The CRDS analyzer and its peripherals, including flow controls and a computer, are placed inside a small rack, and all the pumps are kept beneath this rack (Fig. 1). The standard gas cylinders are horizontally aligned on wooden trays at a short distance from the rack.

To support the interpretation of the greenhouse gas measurements, the tower is also equipped with Gill MetPak II (Gill Instruments, UK) meteorological sensors at each sampling height. The sensors monitor wind speed and direction, air temperature, barometric pressure, and humidity. In addition, a 3-D wind sensor (3-Axis Ultrasonic Anemometer, WindmasterI ${ }^{\mathrm{II}}$, Gill Instruments, UK) is placed at the top of the tower. 
Table 1. Assigned (laboratory-calibrated) dry mole fractions of CO, $\mathrm{CO}_{2}$, and $\mathrm{CH}_{4}$ in $\mathrm{HS}, \mathrm{LS}, \mathrm{WG}$, and T calibration gas standards. Standard errors $(1 \sigma)$ are given in brackets.

\begin{tabular}{lrrr}
\hline & $\mathrm{CO}(\mathrm{ppb})$ & $\mathrm{CO}_{2}(\mathrm{ppm})$ & $\mathrm{CH}_{4}(\mathrm{ppb})$ \\
\hline HS & $250.963(0.234)$ & $472.653(0.013)$ & $2424.718(0.152)$ \\
LS & $160.317(0.627)$ & $382.108(0.007)$ & $1908.908(0.063)$ \\
WG & $81.200(1.902)$ & $392.24(0.024)$ & $2131.200(0.224)$ \\
T & $197.168(0.646)$ & $403.300(0.012)$ & $2140.337(0.053)$ \\
\hline
\end{tabular}

\subsubsection{Calibration}

Span calibrations are carried out once per week using calibration gases supplied from $30 \mathrm{~L}$ aluminum cylinders (ScottMarrin Luxfer, USA) (see also Sect. 2.2.4). Following standard practice, these calibration gases are named as high span (HS) and low span (LS), referring to their relatively high and low mixing ratios of $\mathrm{CO}, \mathrm{CO}_{2}$, and $\mathrm{CH}_{4}$, respectively. These cylinders were filled at Empa, Dübendorf, Switzerland, and calibrated at Empa's World Calibration Center (WCC-Empa) against laboratory standards obtained from NOAA (NOAA Earth System Laboratory, Boulder, CO, USA) traceable to the WMO primary standards WMO-X2007 for $\mathrm{CO}_{2}$ and WMO-X2004 for $\mathrm{CO}$ and $\mathrm{CH}_{4}$. The concentrations of the HS and LS standards were selected to bracket the ambient air values. A working gas (WG) $(50 \mathrm{~L}$, steel cylinder, commercial pressurized air, Carbagas, Switzerland) calibrated at the University of Bern against laboratory standards obtained from NOAA and traceable to the WMO primary standards for $\mathrm{CO}, \mathrm{CO}_{2}$, and $\mathrm{CH}_{4}$ is measured every $6 \mathrm{~h}$ to monitor the instrument's drift. A calibration gas (referred to as target (T) hereafter), also prepared by Empa and filled in a $30 \mathrm{~L}$ aluminum cylinder (Scott-Marrin Luxfer, USA), is measured once a day and shifted by 15 min every day to evenly distribute the measurements over the course of a day through time in order to check the overall system performance and accuracy of the measurements. Target measurements are not included in the computation of calibration factors but analyzed and reported in the same way as ambient air measurements. All these gas cylinders are equipped with dedicated pressure regulators (TESCOM 64-3400). The calibrated concentrations (assigned values) of the span, target gas, and working gas cylinders used since the start of the measurements are given in Table 1.

\subsubsection{Data acquisition}

A custom-made Labview ${ }^{\mathrm{TM}}$ program, installed on an additional computer, controls the valve switching (between standards and ambient air as well as between different heights) according to a preset measurement sequence, communicates with the Picarro analyzer, calculates the mixing ratios of the different species in real time, and performs preliminary data quality checks. It also collects the meteorological data from the different levels of the tower and saves all measurement and control parameters to an output file on the computer itself. The original data have a time resolution of about $5 \mathrm{~s}$. Every 2 weeks, data collected from these measurements are transferred to the central data portal at the University of Bern as well as to Empa for central storage of all data from the CarboCount-CH network.

\subsubsection{Operation cycle and data processing}

The data presented in this manuscript were acquired between 29 November 2012 and 30 June 2014. However, some data points were excluded or are missing due to events such as water entering the sampling inlet system in February 2014. In October 2013, we noticed a problem with the fan of the analyzer's CPU, which led to overheating of the system. However, the problem may have started even before and remained undetected. The Picarro was then taken back to the laboratory at the University of Bern, and the damaged fan was replaced. During this period (1-21 November 2013), another Picarro analyzer (G-2311-f) was used instead to avoid interruption of the measurement. However, this instrument did not measure $\mathrm{CO}$.

A complete standard-sample sequence was WG-HS-LST: 212.5-131.6-71.5-44.6-12.5 m. At the end of the cycle, the system returned to sample ambient air at $212.5 \mathrm{~m}$ and continued to lower heights. Sample measurements were conducted for $3 \mathrm{~min}$ at each height on the tower, which resulted in a total of four measurements per height level within an hour. Calibrations were also conducted for $5 \mathrm{~min}$ between November 2012 and March 2014 but then extended to $6 \mathrm{~min}$ after noticing that $3 \mathrm{~min}$ was not completely sufficient to reach equilibrium after switching from ambient air. As gas equilibration requires some time and to avoid any memory effect from the prior measured gas, only the last $60 \mathrm{~s}$ of the measurements were used in the data analysis for standard gases and ambient air, with a flushing time of $2 \mathrm{~min}(5 \mathrm{~min}$ for calibrations after March 2014).

Raw measurement data were span-calibrated using the HS and LS standard gases. Accordingly, linearly interpolated slopes $(\beta)$ and intercepts $(\alpha)$ derived from the HS and LS were applied to the target gas, working gas, and the ambient air measurements using Eq. (1):

$\chi_{\text {cal }}=\chi_{\text {meas }} \cdot \beta+\alpha$,

where $\chi_{\text {cal }}$ and $\chi_{\text {meas }}$ are the calibrated and raw dry mixing ratios of the target gas, WG, or ambient air measurements, respectively.

Drift correction, which is the difference between the true working gas value $\left(\mathrm{WG}_{\text {true }}\right)$ and the calibrated working gas measurement $\left(\mathrm{WG}_{\mathrm{cal}}\right)$, is usually applied in a second step. However, due to issues associated with the working gas this procedure was discarded and a new approach was devised, as will be explained in Sect. 3.1. 

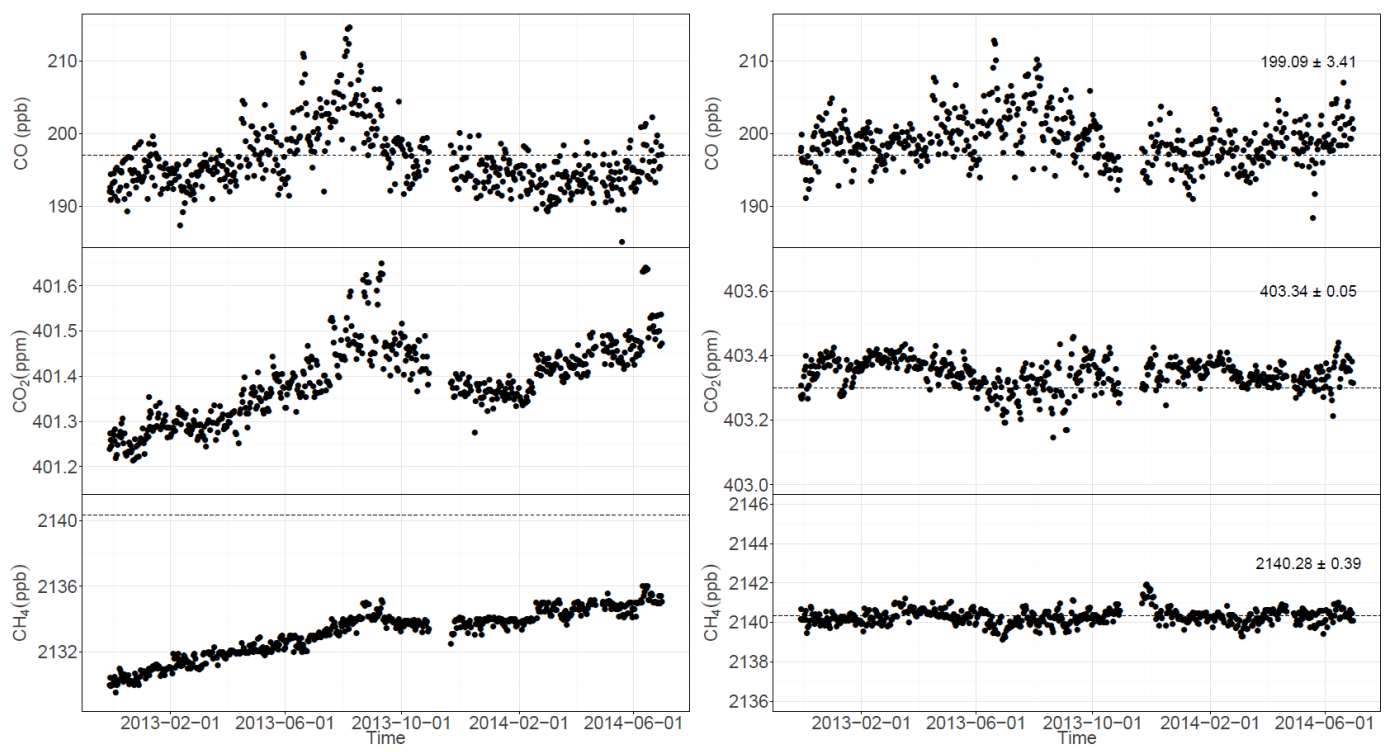

Figure 3. Time series of daily target gas measurements for $\mathrm{CO}, \mathrm{CO}_{2}$, and $\mathrm{CH}_{4}$ for raw instrument readings (left) and span-calibrated values (right). The horizontal dashed line represents the assigned target gas mixing ratios calibrated in the laboratory before deployment to the field. In the case of the raw $\mathrm{CO}_{2}$ measurement, the assigned value $(403.300 \mathrm{ppm})$ is not shown as the offset is much bigger than the measurement scale shown in the figure.

\subsubsection{Quality assessment}

Based on the target gas measurements, we have determined the long-term reproducibility of the measurement system. This term represents the system's average analytical precision and was calculated as the standard deviation of the $1 \mathrm{~min}$ averaged target gas measurements over the entire measurement period.

The measurement accuracy, which describes the total error embracing the measurement precision and trueness (Menditto et al., 2007), was also calculated as

accuracy $=\sqrt{(\text { precision })^{2}+(\text { trueness })^{2}+\sigma_{\text {assigned }}^{2}}$,

where trueness is determined from the absolute difference between the calibrated target gas mixing ratios and the assigned values, with their respective uncertainty given in Table 1 , while $\sigma_{\text {assigned }}$ denotes the uncertainty associated with the assigned value.

\section{Results and discussions}

\subsection{Calibrated data and temperature effect correction}

Figure 3 shows the raw instrument readings of $\mathrm{CO}, \mathrm{CO}_{2}$, and $\mathrm{CH}_{4}$ for the target gas together with the calibrated measurements obtained applying Eq. (1). Apparently, the variability in the raw readings was similar for the three aluminum cylinders used for the HS, LS, and target gas measurements, so that the target values were rather stable after span calibration. However, this might give a false impression of accuracy because the variations in the raw values of HS and LS concentrations are driven by instrumental biases and temperature changes as discussed below. Instrumental biases associated with long-term instrumental drifts shall be easily accounted for by applying a simple span calibration. However, the spancalibrated working gas measurements shown in Fig. 4 clearly depict that, despite this calibration procedure, a strong variability is still present in the measured mixing ratios. While $\mathrm{CH}_{4}$ measurements of the WG are stable after span calibration, $\mathrm{CO}$ and $\mathrm{CO}_{2}$ measurements show significant variation with time. Hence, the standard approach of using WG measurements to correct for instrumental drifts in between the span calibrations (see Sect. 2.2.4) may be problematic and require an additional correction. As shown in the bottom panel of Fig. 4, despite the stable analyzer's cavity temperature during the measurement period, the Picarro data acquisition system (DAS) box temperature (the nominal instrumenttemperature measured within the analyzer) fluctuated significantly between 30 and $60^{\circ} \mathrm{C}$, due to a combination of diurnal and seasonal variability of the outside air temperature (as the measurement system is not kept in an air-conditioned room), and heat produced by the Picarro instrument and its peripherals. As mentioned in Sect. 2.2.4, a problem with the fan of the Picarro CPU in October 2013 might have led to additional warming of the analyzer around this period. Even after span calibration, the WG measurements of $\mathrm{CO}$ and $\mathrm{CO}_{2}$ closely trace the DAS temperature variations, suggesting a strong temperature effect. This strong correlation between the measured mixing ratios and the DAS temperature is further illustrated in Fig. 5. This is most likely asso- 

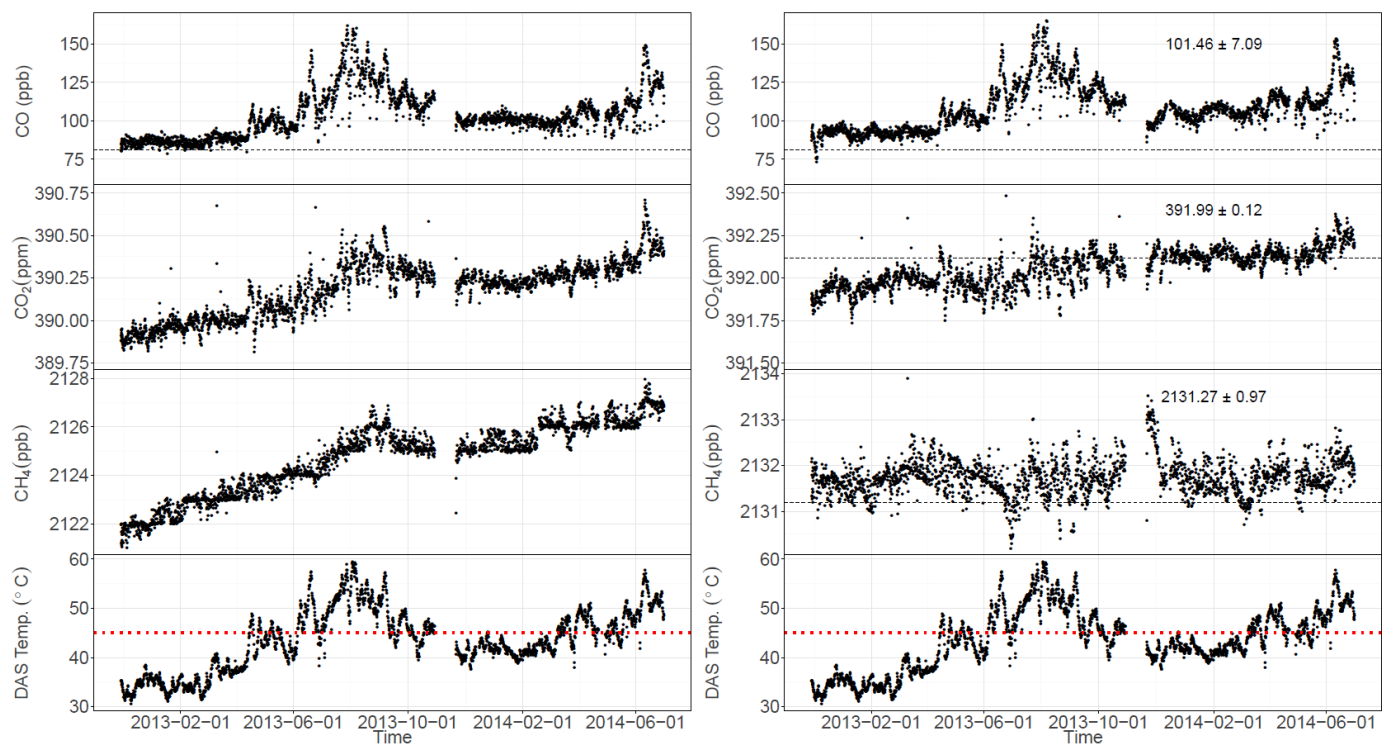

Figure 4. Raw (left) and span-calibrated(right) working gas $\mathrm{CO}, \mathrm{CO}_{2}$, and $\mathrm{CH}_{4}$ mixing ratios. The bottom panel in both figures shows the DAS temperature (black) and the analyzer's cavity temperature records (red) during the measurement period. Note that the CO mixing ratios mirror the DAS temperature record both before and after span calibration of the working gas.

ciated with a temperature-dependent adsorption-desorption effect which was found to be stronger for steel cylinders (i.e., WG) than for aluminum cylinders (target gas) (Leuenberger et al., 2014). According to their study, approximately 10 times more $\mathrm{CO}_{2}$ may be desorbed from steel cylinders than from aluminum cylinders, and a strong linear temperature dependence was observed for steel cylinders $(0.0014$ to $\left.0.0184 \mathrm{ppm}^{\circ} \mathrm{C}^{-1}\right)$, while aluminum cylinders showed only a weak sensitivity $\left(-0.0002\right.$ to $\left.-0.0003 \mathrm{ppm}^{\circ} \mathrm{C}^{-1}\right)$. In addition to the abovementioned temperature effect, drifts or shifts in the instrument's sensitivity were also observed, which can be seen from the layered structure of the raw WG measurements of $\mathrm{CH}_{4}$ (Fig. 5, left panel). As a consequence of the strong temperature effect present in the steel cylinder used for the WG measurements, and of the instrumental biases, a simple drift correction using the WG measurements (as described in Sect. 2.2.4) could not be applied, so a different approach had to be introduced. In addition, correction for the temperature effect present in aluminum cylinders needed to be applied.

This new approach is based on a multiple linear regression model correcting for temperature effects and instrumental biases. For each of the four different standards (HS, LS, T, and WG) a separate regression model was estimated since it is assumed that the temperature effect is dependent on the specific calibration gas cylinder (Leuenberger et al., 2014). The instrument bias term accounts for all the systematic variations in the raw readings not related with temperature; it is estimated based on the WG measurement of $\mathrm{CH}_{4}\left(\mathrm{CH}_{4, \mathrm{WG}}\right)$ since it is expected to be insensitive to the temperature-driven adsorption-desorption effect (Leuenberger et al., 2014). This
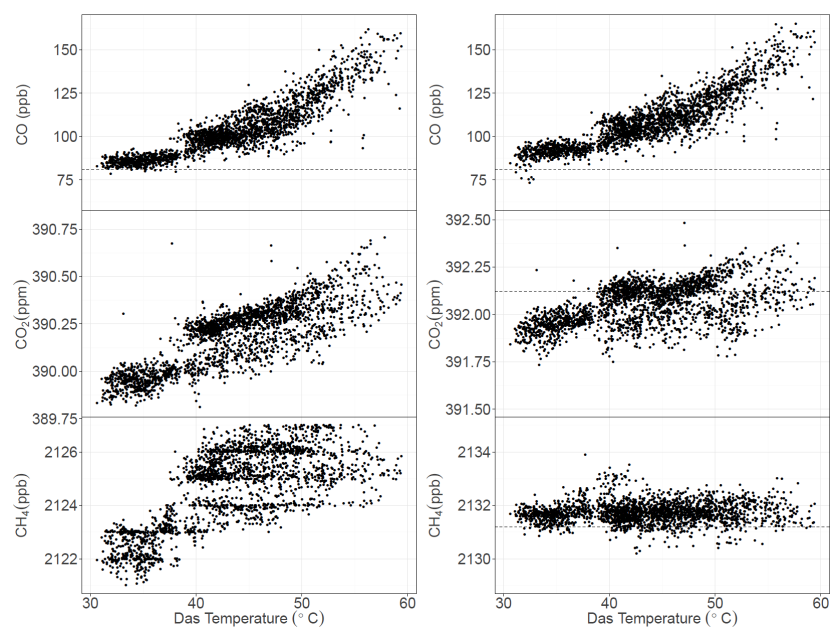

Figure 5. Correlation plot between the raw (left) and spancalibrated (right) working gas $\mathrm{CO}, \mathrm{CO}_{2}$, and $\mathrm{CH}_{4}$ mixing ratios and DAS instrument temperature.

regression model can be expressed mathematically as

$\chi_{\text {meas }}^{i}=\bar{\chi}+a^{i} \cdot T+b^{i} \cdot \mathrm{CH}_{4, \mathrm{WG}}+\varepsilon$,

where $\chi_{\text {meas }}^{i}$ and $\bar{\chi}$ denote the raw and the mean of the raw dry mole fractions of the measured species $\left(\mathrm{CO}, \mathrm{CO}_{2}\right.$, and $\mathrm{CH}_{4}$ ), respectively, and $i$ corresponds to any one of the measured gas cylinders, i.e., WG, T, HS, and LS. The $\varepsilon$ term in this equation describes the residuals of the fit. Equation (3) can also be rewritten as deviations from a mean value as

$\chi_{\text {meas }}^{i^{\prime}} \approx a^{i} \cdot T^{\prime}+b^{i} \cdot \mathrm{CH}_{4, \mathrm{WG}}^{\prime}$, 
Table 2. Analytical precision and accuracy of the measurement system at the Beromünster tower estimated from daily target gas measurements over 19 months. The accuracy is determined using Eq. (2), with the precision obtained using the multiple linear regression approach.

\begin{tabular}{|c|c|c|c|c|c|c|}
\hline \multirow[t]{2}{*}{ Species } & \multirow{2}{*}{$\begin{array}{l}\text { WMO } \\
\text { goal* }^{*}\end{array}$} & \multicolumn{2}{|c|}{ Precision $(1 \sigma)$} & \multirow{2}{*}{$\begin{array}{r}\text { Mean of } \\
\text { calibrated values }\end{array}$} & \multirow{2}{*}{$\begin{array}{c}\text { Assigned } \\
\text { value }\end{array}$} & \multirow[t]{2}{*}{ Accuracy } \\
\hline & & $\begin{array}{r}\text { Span calibration } \\
\text { only }\end{array}$ & $\begin{array}{r}\text { Multiple linear } \\
\text { regression }\end{array}$ & & & \\
\hline $\mathrm{CO}(\mathrm{ppb})$ & \pm 2.0 & 3.41 & 2.79 & 199.14 & 197.17 & 3.48 \\
\hline $\mathrm{CO}_{2}(\mathrm{ppm})$ & \pm 0.1 & 0.05 & 0.05 & 403.34 & 403.30 & 0.07 \\
\hline $\mathrm{CH}_{4}(\mathrm{ppb})$ & \pm 2.0 & 0.39 & 0.29 & 2140.26 & 2140.34 & 0.30 \\
\hline
\end{tabular}

* WMO recommended scientific level of compatibility, GAW report no. 213.

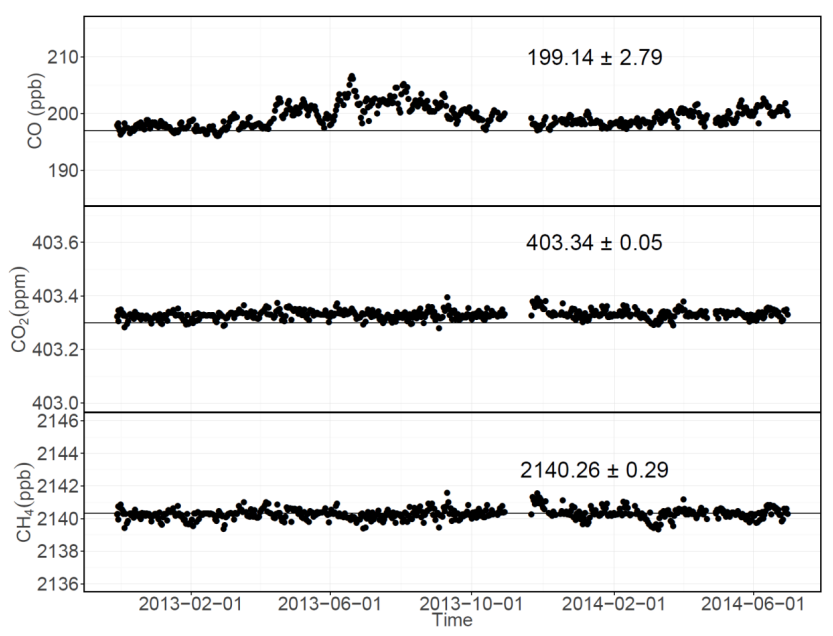

Figure 6. Target gas time series after correction and span calibration following the new two-variable linear regression approach.

where the prime denotes the deviation from the mean (e.g., $\left.\chi_{\text {meas }}^{i^{\prime}}=\chi_{\text {meas }}^{i}-\bar{\chi}\right)$.

The derived slopes $a^{i}$ and $b^{i}$ in Eq. (4) as well as $r^{2}$ values are provided in Table S1 of the Supplement. The model can explain most of the variations observed around the mean mixing ratio measurements; however, only a small fraction of the variance in the CO measurements in HS and LS is explained by the model, expressed by very low $r^{2}$ values. This is most probably associated with the less frequent HS and LS measurements (i.e., once a week) in contrast to WG and target gas.

The corrected mixing ratios were calculated as the difference between measured raw mixing ratios $\left(\chi_{\text {meas }}^{i}\right)$ and the fitted offset values $\left(\chi_{\text {meas }}^{i^{\prime}}\right)$ of each cylinder (Eq. 4$)$, which can be written as

$\chi_{\text {corr }}^{i}=\chi_{\text {meas }}^{i}-\chi_{\text {meas }}^{i^{\prime}}$.

Then, the corrected $\mathrm{CO}, \mathrm{CO}_{2}$, and $\mathrm{CH}_{4}$ mixing ratios were calibrated using the corrected $\mathrm{HS}$ and LS calibration values.

Figure 6 shows the time series of $\mathrm{CO}, \mathrm{CO}_{2}$, and $\mathrm{CH}_{4}$ mixing ratios of the target gas after the multiple regression cor- rection and span calibration procedures mentioned above. The variability in the target gas measurements are reduced when compared to simple span-calibrated mixing ratio measurements, which can also be seen from the calculated precisions in Table 2.

In the case of ambient air measurements, temperature fluctuations may still have an effect on the measured mixing ratios through adsorption-desorption on the gas manifold system which is made of stainless steel or fractionations induced by splitting of high-pressure sample flow into two pathways (Manning et al., 1999). However, the contributions from these effects are significantly lower when compared to deviations from the mean mixing ratio measurements of the ambient air which are strongly dominated by natural variability. Hence, a multiple linear regression fit using Eqs. (4)-(5) could not be applied. Instead, we have used the fitted values $\left(\chi_{\text {meas }}^{i^{\prime}}\right)$ obtained from the target gas measurement to correct for these possible effects. The choice of the target gas for correcting ambient air measurements is twofold: (i) it accounts for the adsorption-desorption effect in the gas manifold unit, and (ii) the adsorption-desorption effect is minimal as it is an aluminum cylinder in contrast to the WG, which may introduce larger errors in the ambient air measurements due to the stronger temperature effect (mainly for $\mathrm{CO}$ and $\mathrm{CO}_{2}$ ).

In order to verify if the multiple linear regression correction and calibration for $\mathrm{CO}, \mathrm{CO}_{2}$, and $\mathrm{CH}_{4}$ had a significant effect on the target gas and ambient air measurements, we have calculated the differences between the calibrated values based on the new approach and the values obtained by a simple span calibration approach. Figure 7 shows the absolute difference in the measured mixing ratios of the target gas obtained from these two approaches as well as the analyzer's DAS temperature. A minor difference was observed between the $\mathrm{CO}_{2}$ and $\mathrm{CH}_{4}$ mixing ratios, and most of the differences are within the WMO measurement compatibility target, shown by the grey shaded region. However, a considerable difference was observed in $\mathrm{CO}$ mixing ratios, probably associated with a stronger temperature effect in $\mathrm{CO}$ than $\mathrm{CO}_{2}$ and $\mathrm{CH}_{4}$. The figure further illustrates that these instances of larger differences (outside the WMO compatibility target values) mostly coincide with periods of higher DAS temper- 


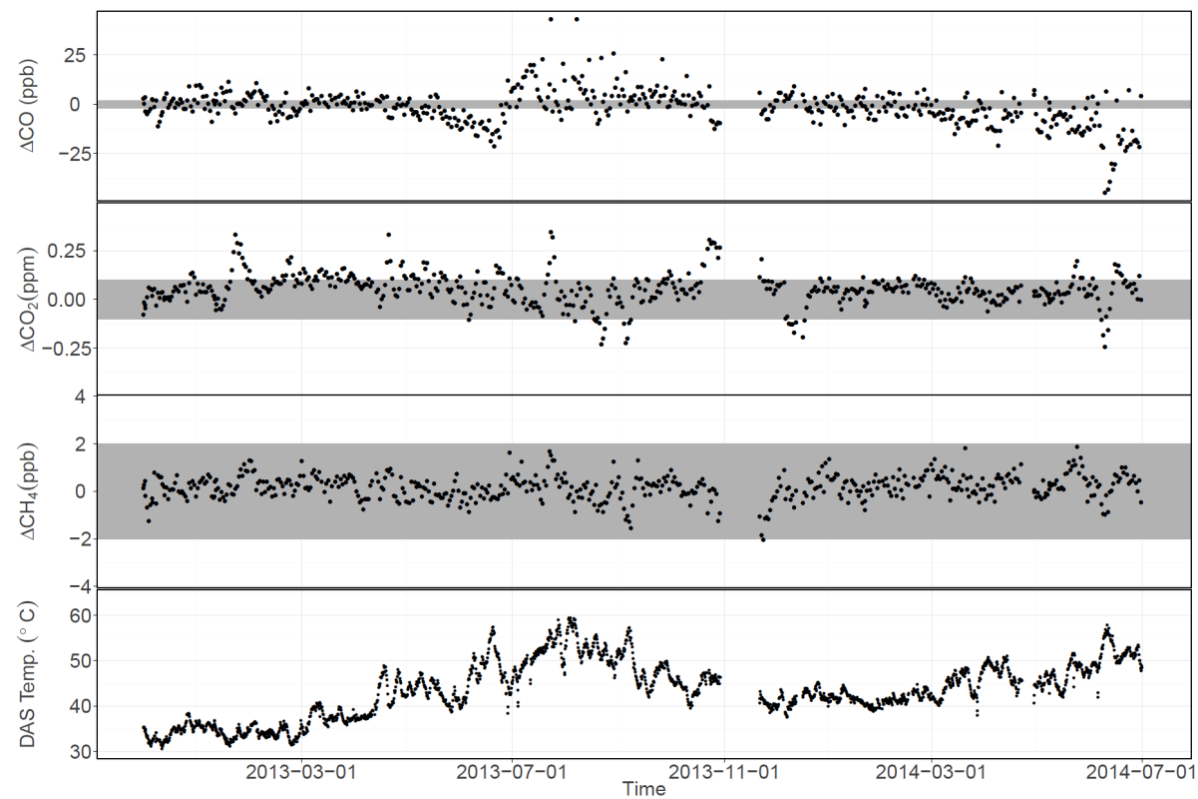

Figure 7. Absolute difference between span-calibrated target gas measurements with and without correction for temperature effects (i.e., span-calibrated without any correction - the multiple regression approach corrected and span-calibrated measurements). The grey shaded region represents the WMO interlaboratory compatibility target for $\mathrm{CO}, \mathrm{CO}_{2}$, and $\mathrm{CH}_{4}$ measurements. The bottom panel shows the analyzer's DAS temperature during the measurement period.

ature records (usually greater than $45^{\circ} \mathrm{C}$ ) such as July till August 2013 and June 2014. However, these differences are relatively small when compared to the variations in the $\mathrm{CO}$, $\mathrm{CO}_{2}$, and $\mathrm{CH}_{4}$ mixing ratios of ambient air, implying only a minor influence on the ambient air measurements by following either of the two approaches.

\subsection{Data quality assessment}

Table 2 summarizes the long-term reproducibility of the target gas measurements during the entire measurement period. The calculated precisions for $\mathrm{CO}_{2}$ and $\mathrm{CH}_{4}$ are within the WMO compatibility target for greenhouse gas measurements. However, the precision calculated for $\mathrm{CO}$ was slightly outside this target, which might be associated with the temperature effect discussed in Sect. 3.1, but it is certainly also due to the lower precision of the $\mathrm{CO}$ measurement.

The accuracy for the target gas measurements determined using Eq. (2) and the multiple linear regression correction and calibration on the raw measurements is dominated by the measurement precision.

\subsection{Ambient air measurements of $\mathrm{CO}, \mathrm{CO}_{2}$, and $\mathrm{CH}_{4}$ mixing ratios}

Figure 8 shows the measured mixing ratios of $\mathrm{CO}, \mathrm{CO}_{2}$, and $\mathrm{CH}_{4}$ for the ambient air at the $12.5,71.5$, and $212.5 \mathrm{~m}$ height levels. The lowest $\mathrm{CO}$ mixing ratios were recorded during summer, associated with the seasonality of the $\mathrm{OH}$ radical, which is the major scavenger of $\mathrm{CO}$ in the troposphere (Lo- gan et al., 1981), and the seasonality of atmospheric transport and mixing. Elevated levels of CO reaching up to $600 \mathrm{ppb}$ were recorded from winter to early spring (mainly January to April) due to low $\mathrm{OH}$ levels; enhanced anthropogenic emissions, e.g., from residential heating with fossil fuels and biofuels; and reduced vertical mixing leading to accumulation of air pollutants in the planetary boundary layer.

The $\mathrm{CO}_{2}$ time series shows a seasonal cycle with maximum mixing ratios in wintertime, and a minimum in summertime. In contrast to $\mathrm{CO}$, the summertime minimum of $\mathrm{CO}_{2}$ is mainly caused by uptake by plants for photosynthesis. The highest $\mathrm{CO}_{2}$ mole fractions $(\sim 460 \mathrm{ppm})$ were observed in winter, and the lowest $(\sim 380 \mathrm{ppm})$ in summer.

In contrast to $\mathrm{CO}$ and $\mathrm{CO}_{2}, \mathrm{CH}_{4}$ showed almost no seasonal trend, but events of high methane peaks occurred in all seasons, which might be associated with local emissions from agriculture and ruminants.

Based on Fig. 8, it is difficult to discern a gradient of these species with height. For all species, especially $\mathrm{CO}_{2}$ and $\mathrm{CH}_{4}$, a stronger variability can be observed in the measurements at $12.5 \mathrm{~m}$ compared to higher levels, which is likely associated with the influence of local sources and sinks at the surface.

Figure 9 shows the monthly mean diurnal cycles of the $\mathrm{CO}, \mathrm{CO}_{2}$, and $\mathrm{CH}_{4}$ mixing ratios at Beromünster in June 2013. The $x$ axis represents time of the day between 00:00 and 24:00 GMT, where midnight corresponds to 23:00 LT. Each data point represents an hourly average mixing ratio where the highest and lowest $5 \%$ of the data were trimmed to minimize the influence of extreme values. $\mathrm{CO}$ mixing ratios 


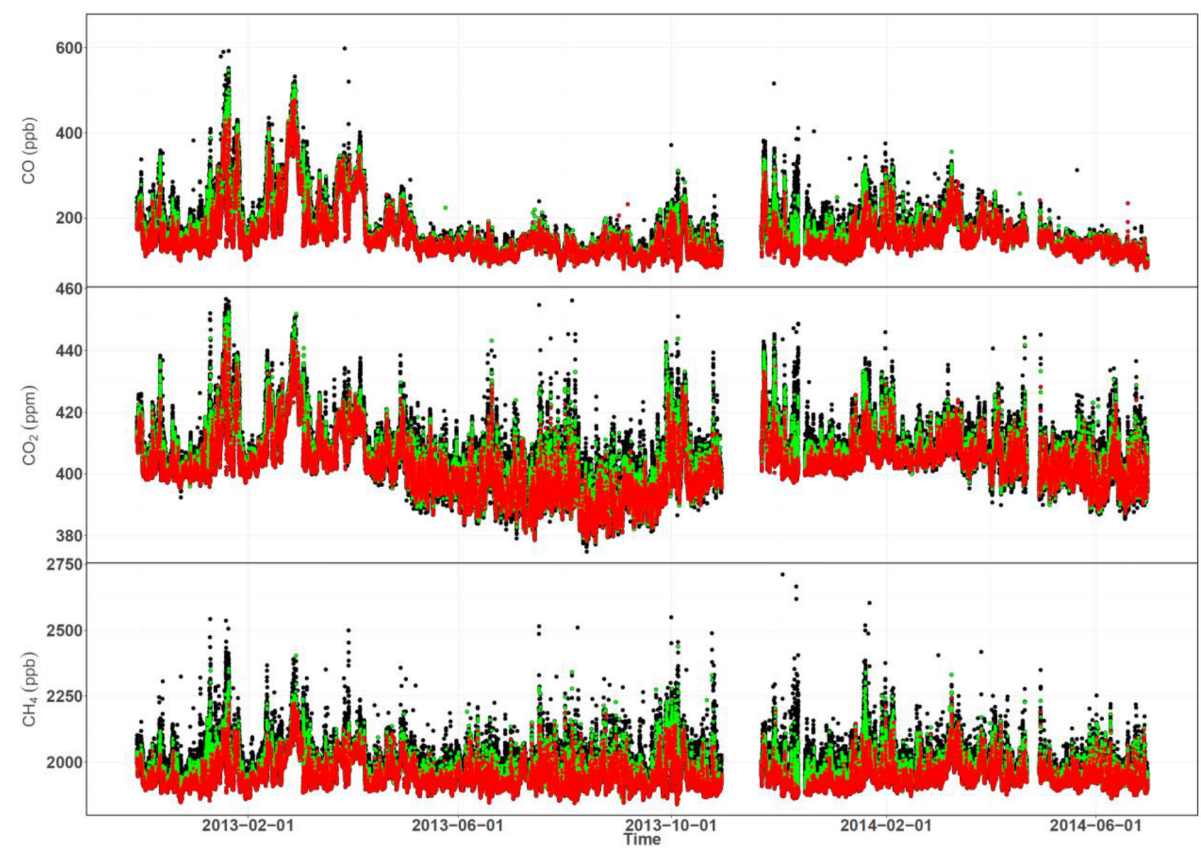

Figure 8. Time series of ambient air measurements at the Beromünster tower at three different height levels: $12.5 \mathrm{~m}$ (black), $71.5 \mathrm{~m}$ (green) and $212.5 \mathrm{~m}$ (red).

exhibit only a weak diurnal trend with two peaks in the morning and evening hours around 9:00 and 18:00 GMT, respectively, possibly associated with regional accumulation of $\mathrm{CO}$ emissions from traffic. Note that, in the vicinity of the tower, traffic is very low. A distinct vertical gradient is present in $\mathrm{CO}$ mixing ratios among the three height levels, with higher mixing ratios at the lowest level throughout the day. This is associated with local to regional ground-based sources and hence higher $\mathrm{CO}$ mixing ratios close to the ground, which is subsequently vertically mixed to higher levels. The vertical gradient is reduced to only a few parts per billion during the day (mainly in the early afternoon) due to strong vertical mixing. The time lag of about an hour between the morning peaks at the highest and lowest level is a result of the evolution of the planetary boundary layer in the morning and the time required for locally emitted $\mathrm{CO}$ to reach the highest level.

In the case of $\mathrm{CO}_{2}$, clear distinctions exist between daytime and nighttime mixing ratios as well as among the three heights due to the combined effects of photosynthesis, respiration, and vertical mixing. During nighttime, $\mathrm{CO}_{2}$ mixing ratios accumulate near the ground level due to plant respiration and probably due to anthropogenic emissions. Vertical mixing is weak, driven by radiative cooling of the surface favoring the formation of a stable boundary layer, and correspondingly a strong gradient at the three height levels. However, the highest level is not completely disconnected from the nocturnal boundary layer, which can be seen from the increase in $\mathrm{CO}_{2}$ mixing ratios at $212 \mathrm{~m}$ during nighttime. As soon as the sun rises in the morning, the stratified nighttime boundary layer starts dissipating, and the $\mathrm{CO}_{2}$ mixing ratios begin to decrease with the onset of photosynthesis by plants. Between noon and late afternoon, the distinct vertical gradients from the previous night completely disappear due to strong surface warming and convective mixing, with nearly the same $\mathrm{CO}_{2}$ mixing ratio at all levels, though with slightly lower values near the surface due to proximity to the vegetation sink.

The $\mathrm{CH}_{4}$ mixing ratios showed a pattern in between those of $\mathrm{CO}$ and $\mathrm{CO}_{2}$. Similar to $\mathrm{CO}_{2}$, they showed an increasing trend during the night from its daytime minimum, reaching its maximum early in the morning. At the lowest level, this maximum occurs about $3 \mathrm{~h}$ earlier than the maximum of $\mathrm{CO}$, suggesting that $\mathrm{CH}_{4}$ sources are closer to the tower than those of CO. During the day, a sharp decrease from this maximum $\mathrm{CH}_{4}$ mixing ratio takes place due to the effect of vertical mixing.

\subsection{Updates to the measurements system and data quality}

In this section we provide a short update about an airconditioning system (AC hereafter) that was recently (on 18 May 2015) installed at the measurement cabin in order to investigate the improvements on the quality of the calibration gas measurements. Since then, better stability of the measurement cabin and the instruments DAS temperature (between 39 and $46^{\circ} \mathrm{C}$ ) has been achieved, instead of the 30 to $60^{\circ} \mathrm{C}$ range recorded before installation of the $\mathrm{AC}$ system. 


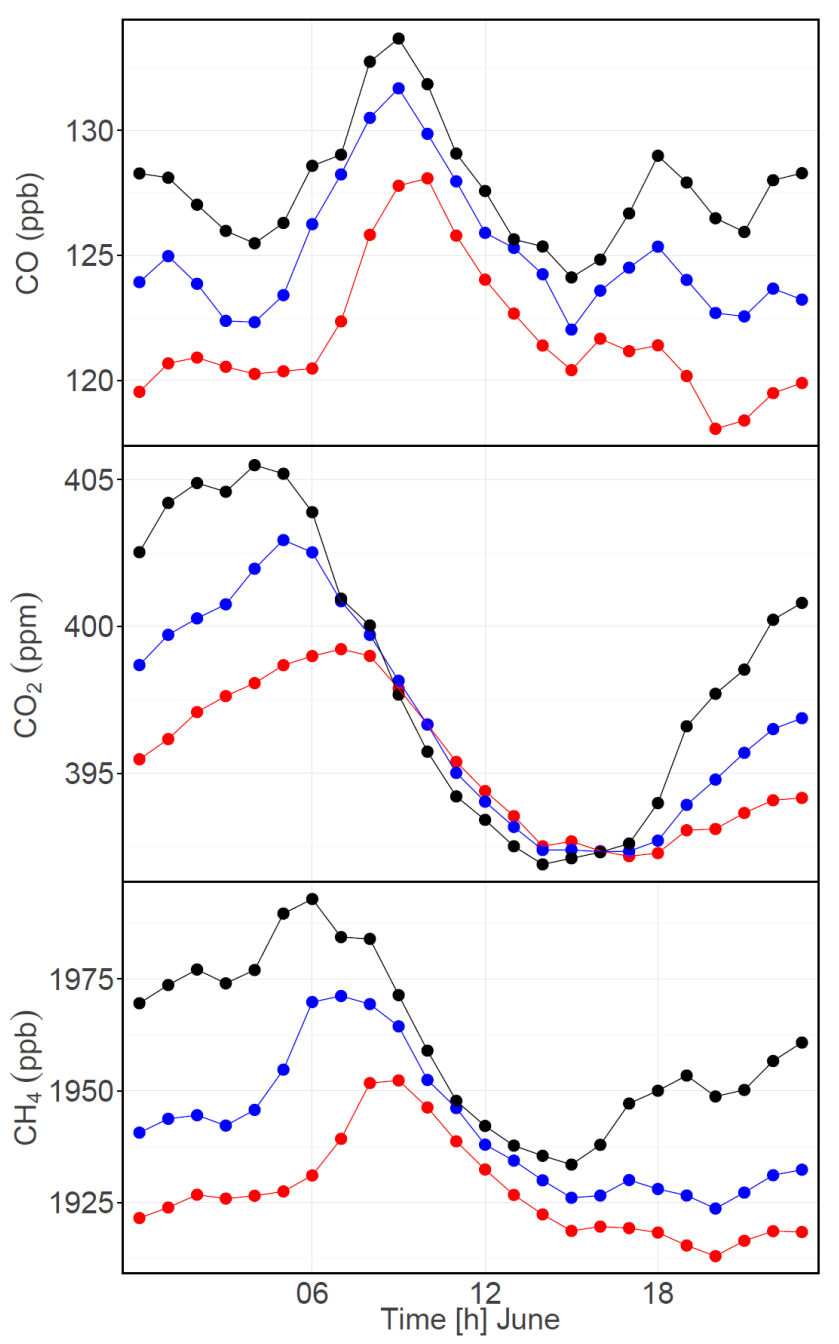

Figure 9. Mean diurnal cycles of $\mathrm{CO}, \mathrm{CO}_{2}$, and $\mathrm{CH}_{4}$ mixing ratios measured at $12.5 \mathrm{~m}$ (black), $71.5 \mathrm{~m}$ (blue), and $212.5 \mathrm{~m}$ (red) on the tower in June 2013. Time is local time (GMT + 01:00), and the lowest and highest $5 \%$ of the data in each hour was excluded before averaging.

When comparing the simple span-calibrated target gas measurements after installation of the $\mathrm{AC}$ with the measurements from the previous period calibrated with the multiple regression approach, no significant improvement was observed in the target gas measurements. This is due to the very low sensitivity of the aluminum cylinders to the temperaturedependent adsorption-desorption effects. However, the steel cylinder working gas showed less improvement in the $\mathrm{CO}$ measurement precision after installation of the $\mathrm{AC}$ when compared to the previous period. The $\mathrm{CO}_{2}$ mixing ratios of the working gas were also already stable with the simple span calibration, which was not the case before installing the $\mathrm{AC}$ system. Additionally, the correlation coefficients for the multiple regression model of the working gas became lower after installation of the AC system, implying a reduced tempera- ture effect on the working gas as well. In general, after installation of the AC system, applying a multiple regression approach has no significant effect on the calibration results of the aluminum cylinder calibration gases since it is unable to explain the observed offsets in terms of instrumental drift and temperature instability.

\section{Conclusions}

The Beromünster tall-tower station for atmospheric measurement of $\mathrm{CO}, \mathrm{CO}_{2}, \mathrm{CH}_{4}$, and $\mathrm{H}_{2} \mathrm{O}$ mixing ratios at five different height levels has been running since November 2012. We have presented the first 19 months of in situ measurements in this study. During this period, we encountered a temperaturedependent adsorption-desorption effect in the calibration gas cylinders affecting the mixing ratio measurements in addition to small instrumental biases requiring an additional correction. This effect was much stronger for steel cylinders (used for the working gas in our case) than for aluminum cylinders used for span calibration and target gas measurements. Hence, we have followed a new correction strategy based on a multiple linear regression approach. This correction was applied for the T, WG, HS, and LS and ambient air $\mathrm{CO}, \mathrm{CO}_{2}$, and $\mathrm{CH}_{4}$ measurements. While looking into the difference between the target gas values obtained applying this new strategy and the span-calibrated target gas measurements without any correction, a minor difference was observed in the $\mathrm{CO}_{2}$ and $\mathrm{CH}_{4}$ measurements. However, the $\mathrm{CO}$ measurements showed slightly higher differences associated with higher sensitivity of the $\mathrm{CO}$ measurements to the temperature effect. Hence, even if the new correction strategy reduces the variability of the target gas measurements, a simple span calibration may already lead to a fairly stable target measurement. From the target gas measurements, we have inferred an overall precision for $\mathrm{CO}_{2}$ and $\mathrm{CH}_{4}$ measurements in agreement with the WMO measurement comparability goals but slightly outside this range for $\mathrm{CO}$. The overall accuracy has been estimated to be $3.48 \mathrm{ppb}, 0.07 \mathrm{ppm}$, and $0.30 \mathrm{ppb}$ for $\mathrm{CO}, \mathrm{CO}_{2}$, and $\mathrm{CH}_{4}$ measurements, respectively. More recently, we have installed an AC system to reduce the temperature effect mentioned above and observed better stability of the measurement cabin and the instrument DAS temperature. However, this did not improve the target gas measurement precision, associated with the minimal sensitivity of the aluminum cylinders to the temperature-induced adsorption-desorption effect. In contrast, a slight improvement was achieved in the precision of the steel cylinder working gas $\mathrm{CO}$ measurements applying the multiple regression approach, while the $\mathrm{CO}_{2}$ measurements were already stable with the simple span calibration method after installation of the AC. Further the cylinder type issue could not be resolved and still exists for the steel cylinder even with the reduced temperature variation range, and the effect remains strongest for $\mathrm{CO}$. 
While this study focuses on technical aspects of the measurements and the data processing, a brief analysis of seasonal and diurnal variations was presented as well.

$\mathrm{CO}_{2}$ showed a summertime minimum and wintertime maximum, modulated by biological activity of plants. Its diurnal variation in summer, with highest mixing ratios during the night and lowest during the day, was also modulated by plants' $\mathrm{CO}_{2}$ uptake during photosynthesis. The diurnal evolution of the vertical gradient in $\mathrm{CO}_{2}$ mixing ratios observed between the five height levels can be explained by the combined influence of sources and sinks at the surface and changes in vertical mixing over the course of the day. $\mathrm{CO}$ also showed a seasonal trend with highest values measured in winter, associated with a seasonality of its $\mathrm{OH}$ sink, reduced vertical mixing, and probably enhanced anthropogenic emissions, whereas $\mathrm{CH}_{4}$ showed almost no seasonal trend.

In general, the Beromünster tower measurement system provided reliable and high-quality measurements of greenhouse gases, and installation of the AC system further improved its stability. The installation of the AC system led to an improved stability of the measurement system. We are now in the process of changing the working standard from steel cylinders to aluminum cylinders, which will minimize the adsorption-desorption effect and further improve the measurement precision and accuracy.

Acknowledgements. This project is supported by the Swiss National Science Foundation through the Sinergia program, CarboCount-CH project (CRSII 2-136273). We would like to thank the staff at the Empa for filling and calibrating the gas cylinders, and Christoph Zellweger (Empa) for providing access to the WCC-Empa calibration infrastructure and supporting the calibrations.

Edited by: R. Dickerson

\section{References}

Andrews, A. E., Kofler, J. D., Trudeau, M. E., Williams, J. C., Neff, D. H., Masarie, K. A., Chao, D. Y., Kitzis, D. R., Novelli, P. C., Zhao, C. L., Dlugokencky, E. J., Lang, P. M., Crotwell, M. J., Fischer, M. L., Parker, M. J., Lee, J. T., Baumann, D. D., Desai, A. R., Stanier, C. O., De Wekker, S. F. J., Wolfe, D. E., Munger, J. W., and Tans, P. P.: CO2, CO, and $\mathrm{CH} 4$ measurements from tall towers in the NOAA Earth System Research Laboratory's Global Greenhouse Gas Reference Network: instrumentation, uncertainty analysis, and recommendations for future high-accuracy greenhouse gas monitoring efforts, Atmos. Meas. Tech., 7, 647-687, doi:10.5194/amt-7-647-2014, 2014.

Bakwin, P. S., Tans, P. P., Zhao, C. L., Ussler, W., and Quesnell, E.: Measurements of carbon-dioxide on a very tall tower, Tellus B, 47, 535-549, doi:10.1034/j.1600-0889.47.issue5.2.x, 1995.

Chen, H., Karion, A., Rella, C. W., Winderlich, J., Gerbig, C., Filges, A., Newberger, T., Sweeney, C., and Tans, P. P.: Accurate measurements of carbon monoxide in humid air using the cavity ring-down spectroscopy (CRDS) technique, Atmos. Meas. Tech., 6, 1031-1040, doi:10.5194/amt-6-1031-2013, 2013.

Gloor, M., Fan, S. M., Pacala, S., and Sarmiento, J.: Optimal sampling of the atmosphere for purpose of inverse modeling: A model study, Global Biogeochem. Cy., 14, 407-428, doi:10.1029/1999gb900052, 2000.

Gloor, M., Bakwin, P., Hurst, D., Lock, L., Draxler, R., and Tans, P.: What is the concentration footprint of a tall tower?, J. Geophys. Res.-Atmos., 106, 17831-17840, doi:10.1029/2001jd900021, 2001.

Haszpra, L., Barcza, Z., Bakwin, P. S., Berger, B. W., Davis, K. J., and Weidinger, T.: Measuring system for the long-term monitoring of biosphere/atmosphere exchange of carbon dioxide, J. Geophys. Res.-Atmos., 106, 3057-3069, doi:10.1029/2000jd900600, 2001.

IPCC: Climate Change 2013: The Physical Science Basis. Contribution of Working Group I to the Fifth Assessment Report of the Intergovernmental Panel on Climate Change, Cambridge University Press, Cambridge, UK and New York, NY, USA, 1535 pp., 2013.

Leuenberger, M. C., Schibig, M. F., and Nyfeler, P.: Gas adsorption and desorption effects on cylinders and their importance for long-term gas records, Atmos. Chem. Phys. Discuss., 14, 19293 19314, doi:10.5194/acpd-14-19293-2014, 2014.

Logan, J. A., Prather, M. J., Wofsy, S. C., and Mcelroy, M. B.: Tropospheric Chemistry - a Global Perspective, J. Geophys. Res.Oceans, 86, 7210-7254, doi:10.1029/Jc086ic08p07210, 1981.

Manning, A. C., Keeling, R. F., and Severinghaus, J. P.: Precise atmospheric oxygen measurements with a paramagnetic oxygen analyzer, Global Biogeochem. Cy., 13, 1107-1115, doi:10.1029/1999gb900054, 1999.

Menditto, A., Patriarca, M., and Magnusson, B.: Understanding the meaning of accuracy, trueness and precision, Accredit. Qual. Assur., 12, 45-47, doi:10.1007/s00769-006-0191-z, 2007.

Oney, B., Henne, S., Gruber, N., Leuenberger, M., Bamberger, I., Eugster, W., and Brunner, D.: The CarboCount $\mathrm{CH}$ sites: characterization of a dense greenhouse gas observation network, Atmos. Chem. Phys., 15, 11147-11164, doi:10.5194/acp-1511147-2015, 2015.

Popa, M. E., Gloor, M., Manning, A. C., Jordan, A., Schultz, U., Haensel, F., Seifert, T., and Heimann, M.: Measurements of greenhouse gases and related tracers at Bialystok tall tower station in Poland, Atmos. Meas. Tech., 3, 407-427, doi:10.5194/amt-3-407-2010, 2010.

Rella, C. W., Chen, H., Andrews, A. E., Filges, A., Gerbig, C., Hatakka, J., Karion, A., Miles, N. L., Richardson, S. J., Steinbacher, M., Sweeney, C., Wastine, B., and Zellweger, C.: High accuracy measurements of dry mole fractions of carbon dioxide and methane in humid air, Atmos. Meas. Tech., 6, 837-860, doi:10.5194/amt-6-837-2013, 2013.

Satar, E., Berhanu, T. A., Brunner, D., Henne, S., and Leuenberger, M.: Continuous $\mathrm{CO}_{2} / \mathrm{CH}_{4} / \mathrm{CO}$ measurements (2012-2014) at Beromünster tall tower station in Switzerland, Biogeosciences, 13, 2623-2635, doi:10.5194/bg-13-2623-2016, 2016.

Tans, P. P.: Uncertainties in the Global Carbon-Cycle, Pure Appl. Chem., 63, 766-768, 1991.

Tans, P. P.: Observational strategy for assessing the role of terresterial ecosystems in the global carbon cycle: scaling down to regional levels, in: Scaling Physiological Processes: Leaf to Globe, 
edited by: Ebleringer, J. R., and Field, C. B., Academic Press, Inc., San Diego, California, 179-189, 1993.

Thompson, R. L., Manning, A. C., Gloor, E., Schultz, U., Seifert, T., Hänsel, F., Jordan, A., and Heimann, M.: In-situ measurements of oxygen, carbon monoxide and greenhouse gases from Ochsenkopf tall tower in Germany, Atmos. Meas. Tech., 2, 573591, doi:10.5194/amt-2-573-2009, 2009.

Vermeulen, A. T. (Ed.): CHIOTTO: Continuous high-precision tall tower observations of 5 greenhouse gases, available at: http: //www.ecn.nl/docs/library/report/2007/e07052.pdf (last access: May 2015), 2004.
Vermeulen, A. T., Hensen, A., Popa, M. E., van den Bulk, W. C. M., and Jongejan, P. A. C.: Greenhouse gas observations from Cabauw Tall Tower (1992-2010), Atmos. Meas. Tech., 4, 617644, doi:10.5194/amt-4-617-2011, 2011.

Winderlich, J., Chen, H., Gerbig, C., Seifert, T., Kolle, O., Lavric, J. V., Kaiser, C., Höfer, A., and Heimann, M.: Continuous lowmaintenance $\mathrm{CO}_{2} / \mathrm{CH}_{4} / \mathrm{H}_{2} \mathrm{O}$ measurements at the Zotino Tall Tower Observatory (ZOTTO) in Central Siberia, Atmos. Meas. Tech., 3, 1113-1128, doi:10.5194/amt-3-1113-2010, 2010. 